\title{
A (IM)PRESCINDIBILIDADE DO LAUDO TOXICOLÓGICO DEFINITIVO, NA CONDENAÇÃO PELOS CRIMES DE TRÁFICO DE DROGAS, NO TRIBUNAL DE JUSTIÇA DO ESTADO DO PARÁ
}

\author{
THE (IN)DISPENSABILITY OF THE DEFINITIVE TOXICOLOGICAL \\ REPORT, IN THE CONVICTION FOR THE CRIMES OF DRUG \\ TRAFFICKING, IN THE COURT OF JUSTICE OF THE STATE OF PARÁ
}

\author{
Luanna Tomaz de Souza \\ Universidade Federal do Pará (Belém, PA, Brasil) \\ Panmella Stephanie Acácio Alves \\ Universidade Federal do Pará (Belém, PA, Brasil)
}

Recebimento: 25 ago. 2019

Aceitação: 4 mar. 2020

\begin{abstract}
Como citar este artigo / How to cite this article (informe a data atual de acesso / inform the current date of access):
SOUZA, Luanna Tomaz de; ALVES, Panmella Stephanie Acácio. A (im)prescindibilidade do laudo toxicológico definitivo, na condenação pelos crimes de tráfico de drogas, no Tribunal de Justiça do Estado do Pará. Revista da Faculdade de Direito UFPR, Curitiba, v. 65, n. 2, p. 49-73, maio/ago. 2020. ISSN 2236-7284. Disponível em: https://revistas.ufpr.br/direito/article/view/68728. Acesso $\quad$ em: 31 ago. $2020 . \quad$ DOI: http://dx.doi.org/10.5380/rfdufpr.v65i2.68728.
\end{abstract}

\section{RESUMO}

O objetivo deste trabalho é analisar o posicionamento do Tribunal de Justiça do Estado do Pará em relação à possibilidade de condenação nos crimes de tráfico de drogas em que o laudo toxicológico definitivo está ausente no processo. Para tanto, será realizada uma pesquisa jurisprudencial nos acórdãos do tribunal, a partir do método dedutivo, considerando o disposto na Lei 11.343/2006 (Lei de Drogas). A hipótese central é a de que o tribunal tem condenado pessoas sem o laudo, como resquício de uma política inquisitorial e proibicionista. No decorrer do artigo serão analisados a moldura inquisitorial do sistema processual penal, os delineamentos da noção de materialidade e verdade e a história da legislação brasileira sobre drogas, em especial a Lei 11.343/2006. Essa pesquisa se apresenta como relevante, ao se considerar que ela diz respeito ao maior tribunal da Região Norte do País e que se está a analisar uma das provas fundamentais para julgamento de um dos crimes que mais aprisiona no Brasil.

\section{PALAVRAS-CHAVE}

Tráfico de drogas. Materialidade. Lei 11.343/2006. Proibicionismo. Inquisitorialismo.

\begin{abstract}
The purpose of this paper is to analyze the position of the Court of Justice of the State of Pará regarding the possibility of conviction in drug trafficking offenses without the definitive toxicological report. To this end, a jurisprudential survey will be carried out in the judgments of the Court, based on the deductive method and considering the provisions of Law 11,343/2006 (Brazilian Drug Law). The central hypothesis is that the Court has condemned people without the report, as remnants of an inquisitorial and prohibitionist policy. In the course of the article, the inquisitorial frame of the
\end{abstract}


criminal procedural system, the delineations of the notion of materiality and truth, and the history of drug legislation in Brazil, in particular Law 11,343/2006, will be analyzed. This research presents itself as relevant, considering that it is about the largest court in the Brazilian Northern Region and that the analysis is about one of the fundamental evidences used at trials of one of the crimes that most imprisons people in the country.

\section{KEYWORDS}

Drug trafficking. Materiality. Law 11,343/2006. Prohibitionism. Inquisitorialism.

\section{INTRODUÇÃo}

O presente trabalho tem o objetivo de analisar o posicionamento do Tribunal de Justiça do Estado do Pará (TJPA) em relação à possibilidade de condenação nos crimes de tráfico de drogas sem o laudo toxicológico definitivo.

Trata-se de estudo realizado por meio do método dedutivo, em que as decisões do TJPA serão analisadas para verificar se estão de acordo com o Código de Processo Penal Brasileiro e a Lei 11.343, de 23 de agosto de 2006, conhecida como Lei de Drogas.

Destaca-se, para tanto, a importância da materialidade do crime no processo penal brasileiro, como o ordenamento jurídico brasileiro se estruturou acerca da proibição ao tráfico de drogas e a relevância do laudo toxicológico definitivo na referida lei.

A comprovação da materialidade de um crime é fator necessário para a condenação de um acusado. Ante a ausência da comprovação da materialidade não há que se falar na existência do crime. Para tanto, o sistema brasileiro adota formas de definir e comprovar a materialidade de um crime, sendo feito, no presente artigo, o debate acerca do crime de tráfico de drogas.

Utilizaram-se as técnicas de pesquisa bibliográfica, documental e jurisprudencial. Para a pesquisa jurisprudencial, foram pesquisadas decisões no site do TJPA, utilizando-se os seguintes termos de buscas: “tráfico de drogas” "laudo toxicológico definitivo” e “materialidade”, selecionando-se ainda os filtros “criminal”, “apelação” e “2017”. A escolha desse ano ocorreu porque, em 2018, o TJPA editou súmula sobre o tema, sendo importante contrastar com o posicionamento mais recente que estava sendo tomado.

As decisões foram analisadas e discriminadas de acordo com o critério adotado para este trabalho, que é o da condenação nos crimes de tráfico de drogas ante a ausência do laudo toxicológico definitivo e o entendimento dos julgadores para assim identificar qual a posição adotada pelo TJPA sobre a imprescindibilidade ou não desse laudo para as condenações nos crimes de tráfico de drogas. 
Essa pesquisa se apresenta como relevante ao se considerar que se trata do maior tribunal da Região Norte do País e que se está analisando uma das provas fundamentais para julgamento de um dos crimes que mais aprisiona no Brasil.

De acordo com análise do Banco Nacional de Monitoramento de Prisões - Cadastro Nacional de Presos -, em 2018, havia 602.217 pessoas cadastradas no sistema como privadas de liberdade, incluídas as prisões civis e internações como medidas de segurança (BRASIL, 2018). No estado do Pará, a quantidade de pessoas privadas de liberdade era de 15.706 (BRASIL, 2018).

Entre os tipos penais mais recorrentes imputados às pessoas privadas de liberdade, o crime de tráfico de drogas encontra-se em segundo lugar, com 24,74\% de todas as pessoas presas (BRASIL, 2018). Levando esses dados em consideração, faz-se necessário realizar uma análise do impacto da política proibicionista de drogas, assim como, quais motivos podem estar interferindo para tamanho número de pessoas presas por esse delito.

\section{INQUISITORIALISMO E A BUSCA DA VERDADE}

É fundamental, ao analisar a gestão da prova no processo penal brasileiro, apontar a relação desta com os sistemas processuais. Conforme ressalta Aroca (2015), os sistemas processuais são produtos culturais de uma época, sendo que os sistemas inquisitório e acusatório levam a um tratamento diferenciado de gestão da prova. O sistema acusatório, mais adequado ao Estado Democrático, tem como norte uma verdadeira separação de funções entre os sujeitos processuais e uma efetiva imparcialidade do julgador, que deverá estar afastado da produção das provas, garantindo o contraditório.

O sistema inquisitório surge ainda no Império Romano, com o poder central romano. Estabeleceu-se, porém, com o cristianismo tornando-se a religião oficial, o que fez com que sobrevivesse por meio do direito canônico e fosse reinserido na Idade Média, mesmo que com interpretação mais política.

Durante a Idade Média, surgiu um direito local que tinha características acusatórias. Entretanto, devido ao conflito de interesses entre os senhores feudais e o rei, a monarquia teve a necessidade de modificar o sistema de processamento, de forma que as funções de legislar, julgar e administrar ficassem em suas mãos. Assim, surgiu a urgência de se modificar o sistema para um que melhor se adequasse às necessidades de unificação do poder jurisdicional, oportunidade em que o sistema inquisitório retornou, por meio do direito canônico (ANDRADE, 2013). 
Tal modelo processual reassume a busca pela verdade, como antes praticado pelos romanos, embora de forma diferenciada, baseada na palavra do ser humano e não na força. Suas imperfeições começaram a aparecer por existirem diversas maneiras de normalizar o sistema inquisitório que variavam de acordo com a visão política de cada país e do limite que a Igreja Católica impunha contra a heresia

Lima (2016) define que a principal característica do sistema inquisitório é a do juiz inquisidor, assim chamado por possuir as funções de acusar, defender e julgar, unicamente em sua pessoa, comprometendo a sua imparcialidade. Tendo o poder probatório em suas mãos, pode determinar a produção de provas em qualquer momento. Em consequência dessa característica, o processo não era regido pelo contraditório e o acusado, na maioria das vezes, era mantido preso preventivamente.

De acordo com Lima (2016), no sistema inquisitório há um foco grande na possibilidade da descoberta da verdade e, por isso, autoriza-se a ampla atividade probatória e os meios cabíveis para que se chegue a esse fim, sendo admitida até a tortura como meio para se chegar à confissão do acusado. O acusado não é considerado, nesse sistema, um sujeito processual, mas sim, um objeto do processo, para se alcançar a verdade.

Quanto ao sistema acusatório, segundo Avena (2017), possui esse nome em virtude da necessidade de formalização de uma acusação com a narração dos fatos e todas as circunstâncias, tendo como principais características: a distinção total das funções de acusar, defender e julgar, sendo realizadas por pessoas diferentes; a garantia ao acusado de um processo com ampla defesa e contraditório; a publicidade dos atos processuais, salvo casos específicos previstos em lei; e a igualdade processual, sendo assegurada a produção de provas pelas partes de forma igualitária e sem interferência do juiz. Como a sustentação do sistema acusatório é o cumprimento das garantias constitucionais, o acusado deve responder ao processo em liberdade, por via de regra, salvo casos específicos que justifiquem a sua segregação.

No Brasil, a posição quanto ao sistema adotado causa divergência e não será o foco principal deste trabalho. Parte da doutrina e a jurisprudência majoritária indicam vigorar no País o sistema acusatório, tendo como fundamento as garantias asseguradas ao acusado pela Constituição Federal, quais sejam: obrigação de motivação das decisões judiciais (art. 93, IX), isonomia processual (art. 5², I), juiz natural (art. 5 XXXVII e LII), devido processo legal (art. 5 , LIV), contraditório e ampla defesa (art. $5^{\circ}, \mathrm{LV}$ ) e presunção da inocência (art. 5, LVII). Para outra parte, temos um sistema misto, pois apesar de a Constituição Federal trazer regras atinentes ao sistema acusatório, o sistema policial possui algumas características do sistema inquisitório e mesmo o sistema processual prevê 
medidas contraditórias, como a produção de provas ex officio pelo juízo. Há ainda autores que indicam a prevalência de um sistema inquisitório, para quem deveria ser assim nomeado o sistema vigente (AVENA, 2017).

Para Binder (2003), o século XX manteve o sistema inquisitório vivo, em especial na América Latina, onde ocorreram períodos ditatoriais em diversos países. Após o fim dessas ditaduras, com a formalização da democracia, muitos países tentaram adotar formas do sistema misto, espelhados no Code Crimenelle bonapartista de 1808. Estes, contudo, nada mais são do que um sistema inquisitório de aparência acusatória (BINDER, 2003).

Em que pese a existência de tais divergências sobre o modelo prevalente no País, o que se quer destacar no presente trabalho são as permanências inquisitoriais, em especial, nesse momento, na produção de provas.

No livre convencimento motivado, sistema da valoração das provas mais aceito, não se estabelece uma hierarquia de provas, deixando-se o juiz formar seu convencimento de forma autônoma diante das provas presentes, porém, de modo fundamentado, respeitando-se diretrizes de validade, licitude, legalidade e produção perante o contraditório (LOPES JÚNIOR, 2016). Para Pacelli e Fischer (2017), tal princípio é a demonstração de um processo penal que adota a forma garantista.

Não existe hierarquia entre os meios de prova, porém, tendo em vista que as provas são os meios de demonstração da verdade processual, é acertadamente cabível que se exijam formas específicas de se provar certos atos. Tal especificidade acerca do meio de prova serve como proteção ao réu, dado que contribui para maior transparência e segurança dos meios de convicção. Convém ressaltar que a especificidade de métodos de provas não viola o princípio do livre convencimento motivado, em virtude da obrigação que o julgador tem de que seu livre convencimento seja pautado nos critérios e exceções previstos em lei de avaliação de prova, não tendo permissão para ignorar tais previsões na formação do seu convencimento (PACELLI, 2018).

A imposição de utilização de determinados meios específicos de provas não implica a presença de hierarquia, e se justifica pela impossibilidade de exigência de que o julgador possua todas as formas de conhecimentos possíveis, não sendo admissível que, em determinados casos, seja suficiente o conhecimento subjetivo do juiz para atestar a veracidade ou existência do ato praticado (PACELLI; FISCHER, 2017).

Ocorre que prevalece uma visão de juiz inquisidor que tudo pode em nome da busca da verdade, a chamada verdade real. Para Pacelli e Fischer (2017), a expressão conhecida como verdade real não deve mais ser acolhida no processo penal, pois diz respeito à forma como a ação delituosa 
ocorreu, seria uma reprodução dos fatos passados, o que não é possível. No âmbito jurídico só poderia ser considerada a verdade judicial, que em relação à sua formação é classificada em verdade formal e verdade material.

A chamada verdade formal é aquela baseada apenas na utilização das normas legais, sem adequação ao caso concreto e ligada ao fato de que a verdade (certeza) decorre da prova colhida e concretizada nos autos, por aquilo que foi fornecido e provado na instrução processual. O juízo criminal deve assim ser formado mediante a apreciação das provas produzidas no decorrer do processo e do seu o entendimento adquirido do fato. Para Aury Lopes Júnior (2016), a verdade formal possui quatro limitações que devem ser expressas, como garantia de controle na sua busca. São elas:

I - a tese acusatória deve estar formulada segundo e conforme a norma; II - a acusação deve estar corroborada pela prova colhida através de técnicas normativamente preestabelecidas;

III - deve ser sempre uma verdade passível de prova e oposição;

IV - a dúvida, falta de acusação ou de provas ritualmente formadas impõem a prevalência da presunção de inocência e atribuição de falsidade formal ou processual às hipóteses acusatórias. (LOPES JÚNIOR, 2016, p. 449-450).

Para o processo penal a única verdade que justifica uma condenação, a ser buscada e reconhecida é aquela cujo objeto é fruto de um processo que tenha resguardado as normas referentes aos acontecimentos e a elas obedecido, de modo que tenham importância na seara penal, algo que é característico do modelo formalista (LOPES JÚNIOR, 2016).

A noção de verdade, nesses termos, serve para estabelecer limites de atuação do Estado no processo penal, garantindo que atue dentro da lei, e não para proporcionar autenticidade ao processo, sendo respeitados os limites processuais legais para a obtenção e busca dessa verdade, não se devendo conferir essa função ao processo, ainda que eventualmente assim ocorra.

Segundo Khaled Júnior (2013), não se deve expulsar a verdade do processo, apenas lhe retirar de seu lugar quase canônico, pois, uma justiça penal correspondente integralmente com a verdade é utópica, mas, de outro lado, uma justiça dissociada de qualquer noção da verdade é arbitrária. O autor assim aponta a necessidade de buscar novas epistemologias para fundar um novo regime de verdade no processo penal, calcado na redução de danos inerentes a esse processo e no necessário rompimento com o discurso da busca da verdade.

\section{PROVA E MATERIALIDADE}

A expressão prova, no campo jurídico, compreende a forma como alguma coisa é reputada genuína, fidedigna, e está ligada com a conduta de demonstrar para o juiz a forma como se deu 
determinado ato. Uma condenação no processo penal exige que o fato esteja provado para o julgador, não basta a simples possibilidade. Tendo isso em vista, é necessário que a parte utilize os meios legais para produção de provas para evidenciar o seu argumento. A finalidade da prova é, portanto, a busca do convencimento do juízo acerca dos acontecimentos (NUCCI, 2015).

Lopes Júnior (2016) considera que, por via de regra, só serão aceitas as provas descritas no rol do Código de Processo Penal (CPP) (provas nominadas); sendo assim, as espécies de provas devem obedecer à relação taxativa. Todavia, caso sejam respeitadas as adequações processuais e constitucionais da prova penal, é possível que se considere como lícita a prova produzida fora do quadro disposto no CPP (provas inominadas), como é o caso da inspeção judicial.

Em contrapartida, Lima (2016) afirma que pode ser admitidos tanto os meios de produção da prova previstos na lei (provas nominadas) quanto os não previstos (provas inominadas), fazendo assim com que o CPP não obedeça ao preceito da taxatividade das provas. No entanto, admite que as provas inominadas devem respeitar as normas constitucionais e terem sido colhidas de forma permitida, observando-se as excepcionalidades previstas no próprio corpo do CPP, como por exemplo no artigo 155, que estabelece previsão quanto ao estado das pessoas nos termos da lei civil.

Acerca dos meios de prova explícitos no CPP, há: perícias em geral (arts. 158 a 184), interrogatório do acusado (arts. 185 a 196), confissão (arts. 197 a 200), ofendido (art. 201), testemunhas (arts. 202 a 225), reconhecimento de pessoas e coisas (arts. 226 a 228), acareação (arts. 229 e 230), documentos (arts. 231 a 238), indícios (art. 239) e busca e apreensão (arts. 240 a 250).

A materialidade de um crime é o que define que tal ato ilícito foi praticado, sendo composta por fundamentos objetivos. É por meio da materialidade comprovada do crime que se chega ao tipo penal. Os vestígios são demonstrações da materialidade do crime, podendo ser permanentes (materiais) ou passageiros (imateriais). A comprovação dos crimes cujos vestígios sejam materiais será feita por meio de perícia (exame de corpo de delito) e quanto aos vestígios imateriais haverá o encargo de serem demonstrados pelas outras formas de provas. Assim, para os crimes materiais há formas diretas de averiguação, enquanto aos imateriais, a comprovação da materialidade será investigada por formas indiretas lícitas de obtenção de provas (NUCCI, 2015).

Pacelli e Fischer (2017) afirmam que, além de o exame técnico ser compreendido como meio de demonstração da materialidade, também pode, em algumas circunstâncias, servir para comprovar a autoria ou participação nos crimes. É tamanha a importância do exame pericial nos crimes que 
deixam vestígios, que o legislador, no artigo 564, inciso III, alínea $b$, do CPP, impôs a nulidade diante da ausência de laudo pericial, que não poderá ter sua ausência preenchida por testemunho pessoal ${ }^{1}$.

O exame de corpo de delito, próprio dos crimes materiais, distingue-se das perícias gerais, pois é realizado em contato com os meios constitutivos da materialidade do crime, sendo, por esse motivo, a prova pericial que possui o maior grau de relevância. Destarte, a regra geral insiste na obrigatoriedade da presença do exame de corpo de delito direto para a comprovação da existência dos crimes que deixam vestígios, podendo sua ausência inclusive implicar nulidade absoluta do processo (LOPES JÚNIOR, 2016).

Os clamores punitivistas, contudo, solapam essas diretrizes, levando a condenações sem os rigores estabelecidos em lei para comprovação. Segundo Shimizu (2015), há uma manipulação ideológica arranjada a partir do punitivismo, que encontra êxito em transformar o invisível em um monstro imaginário. Aquele cuja existência se negava passa a ser o inimigo, e isso leva o magistrado a entender que sua função é, de fato, puní-lo, independentemente das provas produzidas. Amaral (2011) ainda destaca ser justamente essa instabilidade, atribuída à função judicial no encalço da prova, que identifica o perfil inquisitório do processo penal brasileiro.

\section{A PROIBIÇÃo AO TRÁfiCO DE DROGAS E A LEI 11.343/2006}

É fundamental, ao pensar a política de drogas na contemporaneidade, refletir sobre o alcance do paradigma proibicionista. Segundo Fiore (2011), “o proibicionismo não esgota o fenômeno contemporâneo das drogas, mas o marca decisivamente”. Segundo o autor, a radicalização política do puritanismo norte-americano, o interesse da nascente indústria médico-farmacêutica pela monopolização da produção de drogas, os novos conflitos geopolíticos do século XX e o medo das elites diante da desordem urbana são fatores que levaram à consolidação desse modelo, que é focado no endurecimento penal no que tange ao uso e comercialização de determinadas substâncias.

\subsection{O PROIBICIONISMO NA ESFERA INTERNACIONAL}

Conforme Valois (2017), a política proibicionista das drogas tem como marcos, na esfera internacional, a Convenção de Xangai, em 1909, responsável por acordar multilateralmente entre os países a proibição ou regulação cuidadosa do ópio para qualquer utilização que não fosse a medicinal.

\footnotetext{
1 “Art. 158, CPP. Quando a infração deixar vestígios, será indispensável o exame de corpo de delito, direto ou indireto, não podendo supri-lo a confissão do acusado.”
} 
Posteriormente, foi realizada a Conferência de Haia, em 1911, que teve como resolução a proibição da exportação de ópio para os países que o considerassem ilegal, além da intenção de limitar a produção. Em sequência, a Segunda (1913) e Terceira (1914) Conferências de Haia buscaram a ratificação dos outros países acerca da primeira Conferência de Haia. É importante ressaltar que os países que ainda não haviam assinado e ratificado a Convenção de Haia, viram-se obrigados a fazêlo quando da assinatura do Tratado de Versalhes, de acordo com a previsão expressa no artigo 295 do tratado, fazendo com que o tema das drogas entrasse de forma definitivamente no ordenamento jurídico mundial.

Entre 1924 e 1925, ocorreu a Conferência Internacional do Ópio, em Genebra. Em 1931, aconteceram mais dois encontros, a Convenção para Limitar a Manufatura e Regular a Distribuição de Narcóticos, em Genebra, e a Conferência para Supressão do Fumo de Ópio, em Bangkok, Sião (hoje Tailândia). Com a Convenção para a Repressão do Tráfico Ilícito das Drogas Nocivas, realizada em Genebra em 1936, o tráfico de drogas ganhou reconhecimento internacional, em um grande processo de demonização do tráfico e do uso (VALOIS, 2017).

Em Nova York, em 1961, ocorreu a Convenção Única sobre Entorpecentes, já com o anteparo das Nações Unidas e com um grande número de países signatários, que tinham como temor a saúde e a "moral" da humanidade, caracterizando a droga como um "mal que contamina a todos que dela se aproximam” (VALOIS, 2017, p. 256). Seu modelo de classificação das drogas em listagem perdura até a atualidade, sendo distintas de acordo com o "potencial de abuso e suas aplicações médicas”. Ressaltam Boiteux, Chernicharo e Alves (2017) que embora tenha sido colocada na convenção a preocupação com a saúde física e mental da população, só utilizou-se o controle e a repressão penal em forma de proibição total do uso e comércio de tais substâncias.

A Convenção sobre Substâncias Psicotrópicas aconteceu em Viena, em 1971, porém, seu foco, diferentemente do da convenção anterior, estava no controle administrativo dos psicotrópicos, e não em normas penais. Sua lista possuía 32 substâncias, divididas em quatro categorias. Valois (2017, p. 285) continua explicando o porquê de tal diferenciação:

\begin{abstract}
O argumento que sempre baseou a guerra às drogas não se encaixa na situação das drogas psicotrópicas porque não há como se atacar a oferta atingindo regiões além da fronteira, porque o "mal”, nesse caso, mora no interior do próprio país que se diz combatente. O que há de ficar claro como lição é que o crescimento do consumo dessas substâncias, com ou sem prescrição médica, se deu também por causa do combate às drogas em geral.
\end{abstract}

Por meio do Protocolo de 1972, que emendou a Convenção Única de 1961, a característica extremamente coercitiva foi amenizada no que diz respeito aos usuários e na forma como os Estados agiam em relação a eles. Isso possibilitou substituir a prisão dos usuários por medidas de tratamento, 
assim como proporcionar tratamento e reabilitação aos usuários de drogas (BOITEUX; CHERNICHARO; ALVES, 2017).

Conhecida como Convenção de Viena, a Convenção Contra o Tráfico Ilícito de Entorpecentes e Substâncias Psicotrópicas, realizada em 1988, foi direcionada à repressão, assim como a Convenção Única. A posse de drogas foi pela primeira vez criminalizada.

Boiteux, Chernicharo e Alves (2017) salientam que o direcionamento da Convenção de Viena é “a necessidade da criminalização mais intensa sobre o comércio e a produção de substâncias ilícitas” e explicam o que seria a intenção dessa convenção:

Seu texto foi projetado para se tornar uma ferramenta repressiva com o objetivo de “combater” organizações de tráfico de drogas, expandindo as hipóteses de extradição, cooperação internacional e o confisco de ativos financeiros de traficantes, além de unificar e fortalecer os instrumentos jurídicos existentes (BOITEUX; CHERNICARO; ALVES, 2017, p. 236).

Assim, atualmente, na esfera internacional, as três convenções vigentes são: a Convenção Única sobre Entorpecentes, de 1961, a Convenção sobre Substâncias Psicotrópicas, de 1971 e a Convenção Contra o Tráfico Ilícito de Entorpecentes e Substâncias Psicotrópicas, de 1988.

Percebe-se assim que a sociedade internacional, desde o início do século XX, tem dedicado um grande montante e muita disposição para tratar das condições coercitivas previstas nas convenções, determinando que os países controlem e punam rigorosamente os usuários de drogas ilícitas, assim como aqueles que as vendem, sem se preocupar com atuações no campo do cuidado. Essa lógica proibicionista reverberou internacionalmente, levando ao aumento no número de prisões e ao fortalecimento da lógica que coloca o traficante como um grande “inimigo" da sociedade (BRITO NETO et al., 2016).

\subsection{O DESENVOLVIMENTO DO PROIBICIONISMO NO BRASIL}

O processo de proibição do uso dessas substâncias no Brasil é farto no que se refere à criminalização do usuário e à construção de estigmas. Segundo Maurício Fiore (2005), o proibicionismo do uso de drogas, no Brasil, encontra sua emergência no século XIX. Em 1830, houve a proibição do uso da cannabis, associada, à época, ao consumo pelas classes mais baixas e discriminadas da sociedade ${ }^{2}$.

2 Em 1830, foi instituída pela Câmara Municipal do Rio de Janeiro a Lei do Pito do Pango, a qual prelecionava que: “É proibida a venda e o uso do pito do pango, bem como a conservação dele em casas públicas. Os contraventores serão multados, a saber: o vendedor em 20\$000, e os escravos e mais pessoas, que dele usarem, em três dias de cadeia”. 
Já na República, em 1890, com a aprovação do primeiro código penal republicano, foi tornada crime contra a saúde pública a venda de substâncias venenosas e não autorizadas, sendo apenado esse ato, por meio de multa (CARVALHO, S., 2013).

Quanto ao início do século XX, é importante ressaltar que as legislações brasileiras eram também construídas sob a lógica da proibição do uso e da criminalização do comércio das drogas, levando os usuários às prisões ou sanatórios. Era o chamado higienismo, que, desde 1900, estava na pauta principal da condução do Estado (RAMOS, 2012).

No Brasil, com a emergência de um contexto de higienização social, o Código Sanitário da República, de 1890, passou a disciplinar o uso do espaço urbano segundo padrões europeus, condenando o uso público de drogas. Na década de 1920, contudo, a situação se modificou. Com a Convenção de Haia (1912), fortaleceu-se o controle sobre opiáceos e cocaína, surgindo a primeira lei de controle.

Adiante, observa-se que paulatinamente a legislação brasileira assumiu um papel de seletividade em relação ao consumo de drogas, com foco na população negra. Faz-se constatar que, mesmo com o advento do higienismo e da influência das legislações mundiais, a elite consumidora foi excluída, de fato, desse processo de proibição do consumo.

Em 1932, com a Consolidação das Leis Penais, foi alterado o caput do artigo 159 do Código de 1890. Ocorreu então a substituição do termo "substâncias venenosas” para o termo "substâncias entorpecentes” (o qual perdurou até a revogação da Lei n. 6.368/76), bem como a previsão de pena de prisão (CARVALHO, S., 2013).

Em 1936, foi criada a Comissão Nacional de Fiscalização de Entorpecentes, por meio do Decreto $\mathrm{n}^{0}$ 780. Entre as funções dessa comissão, estava a criação de planos para concretizar as leis nacionais sobre drogas e sujeitá-los ao Legislativo. Durante o período ditatorial de Getúlio Vargas foi editado o Decreto $n^{\circ}$ 2.994/1938, que promulgava a convenção para a repressão do tráfico ilícito das drogas nocivas, de 1936, e que foi seguido pelo Decreto-Lei $n^{\circ}$ 891, que aprovava a Lei de Fiscalização de Entorpecentes, que tinha a função de capacitar o País a controlar de forma hábil a inspeção de entorpecentes. Tal decreto-lei foi o primeiro nacionalmente a proibir o plantio, tráfico e consumo das substâncias elencadas (CARVALHO, J., 2011).

Em 1961, após o então presidente Jânio Quadros tomar posse, ele providenciou, por meio do Decreto $n^{\circ} 50.620$, em conjunto com o Decreto $n^{\circ} 51.211$, a proibição ao uso do lança-perfume e à briga de galos, demonstrando o caráter moralista do cenário proibicionista acerca da cultura e liberdade dos indivíduos, praticado pelo Estado (BRITO NETO et al. 2016). 
Somente após o Golpe Militar a política rígida de controle das drogas foi devidamente aplicada. Até então, os usuários, dependentes e experimentadores não eram criminalizados. Destarte, a partir de 1964, a política criminal de drogas, no Brasil, passou por uma transformação, deixando de ser considerado um assunto sanitário para passar a ser bélico. Como consequência dessa mudança de visão, foi criada a Lei $n^{\circ} 4.483 / 64$, que foi a responsável por modificar o Departamento Federal de Segurança Pública para criar o Serviço de Repressão a Tóxicos e Entorpecentes. Observa-se que o Brasil já estava seguindo nessa direção rígida, desde 1921, devido ao plano internacional de criminalização das drogas adotado pelos EUA (CARVALHO, J., 2011).

Em 1976, foi publicada a Lei n 6.368/76, que previa a criação de um Sistema Nacional de Prevenção, Fiscalização e Repressão, que nada mais era do que o cumprimento das convenções internacionais de 1971 e 1972, mas, apesar de a política repressiva às drogas ter sido projetada na ditadura, apenas no período FHC foi colocada em prática, com a criação de leis e normas sobre drogas (CARVALHO, J., 2011).

Por meio do Decreto $n^{\circ}$ 85.110/80, que regulamentava o artigo $3^{\circ}$ da Lei $6.368 / 76^{3}$, as políticas públicas sobre drogas foram concretizadas, em decorrência do nascimento dos Conselhos Estaduais de Entorpecentes, que visavam ao controle social nas políticas públicas sobre drogas (BRITO NETO; SOUZA, 2015).

Já em 2002, foi promulgada a Lei 10.409, que preservava a natureza infracional do porte de drogas para uso pessoal, porém, inovava com a previsão de medida criminal não focada na prisão, seguindo o procedimento da lei referente aos crimes de menor potencial ofensivo, levando em consideração as medidas alternativas.

Ocorre que, embora tenha sido aprovada pelo legislativo, os artigos dessa lei pertinentes aos delitos e às penas foram vetados pelo Presidente da República, entrando em vigência apenas o concernente à parte processual, continuando, a parte material, regulada pela Lei 6.368/76, reafirmando assim o seu intuito proibicionista (CARVALHO, S., 2016).

Conforme discutido, a política proibicionista de drogas se deu, no Brasil, por diversas influências, fossem elas externas (como por exemplo as convenções internacionais e pressão norteamericana) ou internas (relacionadas à moral ou ao regime autoritário/ditatorial e sua rigidez).

\footnotetext{
“Art. $3^{\circ}$. As atividades de prevenção, fiscalização e repressão ao tráfico e uso de substâncias entorpecentes ou que determinem dependência física ou psíquica serão integradas num Sistema Nacional de Prevenção, Fiscalização e Repressão, constituído pelo conjunto de órgãos que exerçam essas atribuições nos âmbitos federal, estadual e municipal.”
} 
A Lei 11.343 foi promulgada em 23 de agosto de 2006, revogando assim as anteriores (Lei 6.368/76 e 10.409/02), sendo responsável por instituir o Sistema Nacional de Políticas Públicas sobre Drogas (Sisnad), prescrever medidas de prevenção do uso indevido, atenção e reinserção social de usuários de drogas, e estabelecer normas para repressão à produção não autorizada e ao tráfico ilícito de drogas, além de definir crimes e dar outras providências.

Essa lei define como drogas "todas as substâncias ou produtos com potencial de causar dependência, com a condição de que estejam relacionadas em dispositivo legal competente” (ANDREUCCI, 2018, p. 227). Destaca-se que, embora tenha sido realizada a modificação na nomenclatura para drogas (sendo eliminado o termo entorpecente), o tipo penal continuou seguindo o do modelo anterior, que concebeu tipos penais em branco. A configuração do tipo penal fica dependente de portaria do Serviço de Vigilância Sanitária, do Ministério da Saúde (sendo a Portaria vigente a 344/98).

Fiore (2011) destaca algumas características da atual Lei de Drogas (Lei 11.343/06), como o fato de ter significado mais rigor na guerra ao tráfico e de ter continuado a criminalizar o uso de drogas, ainda que retirando a possibilidade de prisão. Para Gonçalves e Baltazar Junior (2017, p. 88), entre as principais inovações da Lei de Drogas estão:

o tratamento diferenciado em relação ao usuário, a tipificação de crime específico para a cessão de pequena quantia de droga para consumo conjunto, o agravamento da pena do tráfico, a criação da figura do tráfico privilegiado, a tipificação do crime de financiamento ao tráfico, bem como a regulamentação de novo rito processual.

Percebe-se um claro endurecimento com a edição da nova lei. Com o advento da Lei 11.343/2006 cresceu a repressão e o número de presos por tráfico de drogas, principalmente jovens negros. Desde a edição da lei, a prisão por tráfico aumentou $339 \%{ }^{4}$.

A política de drogas brasileira insere-se em um modelo de "política criminal autoritária”. Ferrajoli (2002) assim define políticas criminais que desvalorizam, em maior ou menor intensidade, o princípio da legalidade estrita ou um de seus corolários, buscando dar uma eficácia absoluta ao direito penal. Pleiteia-se a máxima efetividade do controle social. As políticas criminais autoritárias também preveem a prisão como a única alternativa para a solução de conflitos, ignorando a complexidade com que eles ocorrem e as inúmeras possibilidades de enfrentamento.

Para Zaffaroni (2007), os componentes autoritários acompanham o direito penal ao longo de sua história e permanecem mesmo com a construção de novos Estados pautados em um modelo

4 Conforme matéria jornalística publicada no início de 2017, “Um em cada três presos do país responde por tráfico de drogas”. Disponível em: https://glo.bo/2YfvreD. Acesso em: 16 jan. 2020. 
democrático. Esse ranço autoritário se revela em diversos elementos, com a permanente construção de inimigos. No âmbito da política de drogas, o mundo, sob influência dos EUA, começou, a partir da década de 1980, a estruturar uma legislação penal claramente autoritária, elegendo o traficante como inimigo a ser exterminado, com a violação de vários princípios estabelecidos pelas novas constituições. Segundo Batista (1998, p. 123): “[...] sejam eles jovens negros e pobres das favelas do Rio de Janeiro, sejam camponeses colombianos, sejam imigrantes indesejáveis no Hemisfério Norte”.

Esse autoritarismo penal não contribuiu para inibir o consumo, pelo contrário, e ainda ampliou o encarceramento e construiu uma lógica que aperfeiçoou o viés punitivo do sistema penal.

\subsection{A COMPROVAÇÃO DO CRIME DE TRÁFICO DE DROGAS}

Em que pese todo o debate acerca da natureza imprecisa do conceito de drogas, o objeto material do crime de tráfico são as substâncias entorpecentes, psicotrópicas, precursoras e outras sob controle especial da Portaria SVS/MS n ${ }^{\circ}$ 344, de 12 de maio de 1998, e envolve múltiplas condutas, nos termos da Lei 11.340/2006 (ANDREUCCI, 2018, p. 250):

Art. 33. Importar, exportar, remeter, preparar, produzir, fabricar, adquirir, vender, expor à venda, oferecer, ter em depósito, transportar, trazer consigo, guardar, prescrever, ministrar, entregar a consumo ou fornecer drogas, ainda que gratuitamente, sem autorização ou em desacordo com determinação legal ou regulamentar.

De acordo com o artigo 50, $\S \S 1^{\circ}$ e $2^{\circ}$, da Lei 11.343/2006, a materialidade do crime de tráfico de drogas poderá ser comprovada mediante laudo. O laudo provisório de constatação da natureza e da quantidade de droga será utilizado para a lavratura do auto de prisão em flagrante e consequente oferecimento da denúncia, devendo ser realizado, posteriormente, laudo definitivo.

Andreucci (2018) diferencia o laudo provisório do laudo definitivo, sendo que quanto ao primeiro, embora seja considerado necessário para o auto de prisão em flagrante, o Supremo Tribunal Federal (STF) ${ }^{5}$ compreendeu que é dispensável quando a natureza da droga for induvidosa. Já o laudo de exame químico toxicológico é:

o laudo definitivo sobre a toxicidade da substância apreendida, imprescindível para o julgamento do feito, cuja ausência enseja a nulidade da condenação. Esse laudo é fundamental para a comprovação da materialidade do delito, não se confundindo com o laudo de constatação, que tem caráter provisório e serve apenas de suporte ao auto de prisão em flagrante e à denúncia (ANDREUCCI, 2018, p. 301).

5 STF. Habeas corpus 131.941. Relator: Min. Teori Zavascki. Publicado em: 23/08/2016. 
Sobre o laudo provisório, Gonçalves e Baltazar Junior (2017) explicam que é realizado de forma mais simples, rápida, não tendo então cunho científico, podendo ser realizado tanto por perito oficial quanto, na ausência do perito oficial, por pessoa idônea. Tendo em vista que a existência do crime só pode ser considerada caso tenha sido confirmado o princípio ativo da substância (que exige um procedimento mais demorado), a lei admite a possibilidade de utilização do laudo provisório para a lavratura do auto de prisão em flagrante. Dessa forma, o laudo provisório é considerado condição de procedibilidade, tendo em vista que, caso esteja ausente, não será possível o recebimento da denúncia.

Assim, de acordo com a Lei 11.343/06, artigos 50, §§2 e $3^{\circ}$ e 56, é necessária a elaboração, para instrução do processo criminal, de laudo definitivo, que é aquele que resulta de exame químicotoxicológico, feito de forma técnica e detalhada, sendo o responsável por determinar a materialidade do delito. Quando da elaboração do laudo, é necessário que se indique a existência do princípio ativo, a quantidade da droga e a metodologia empregada para a realização do exame.

O momento previsto para a juntada do laudo é anterior à audiência de instrução e julgamento, para que as partes tenham conhecimento do seu conteúdo, sendo admitido, no entanto, que a audiência seja “dividida” para que os debates e o julgamento sejam realizados após a juntada do laudo definitivo (GONÇALVES; BALTAZAR JUNIOR, 2017). Assim, pode se chegar à conclusão de que, em relação à demonstração da materialidade do crime de tráfico de drogas para o recebimento da denúncia, é necessário apenas o laudo provisório. Já para o julgamento do feito, é imprescindível que tenha sido realizado o laudo definitivo, que irá indicar a natureza da substância apreendida e, portanto, demonstrar se a materialidade do fato foi comprovada, ou seja, se a substância apreendida está proscrita na Portaria 344/98 da Anvisa.

\section{A CONDENAÇÃO POR TRÁFICO DE DROGAS SEM LAUDO TOXICOLÓGICO DEFINITIVO}

Levando-se em consideração as especificidades relativas ao crime de tráfico de drogas quanto à comprovação da sua materialidade, será analisado nesta seção como o Tribunal de Justiça do Estado do Pará decidiu, ao longo de 2017, acerca da materialidade do crime de tráfico de drogas e a imprescindibilidade, ou não, do laudo toxicológico definitivo como comprovação da materialidade desse crime.

Para o presente trabalho, foi realizada consulta no site do TJPA, utilizando-se os seguintes termos na área de pesquisa: “tráfico de drogas”, “ausência de laudo toxicológico definitivo” e 
“materialidade”. Foram ainda selecionados os filtros “criminal”, “apelação” e “2017”, obtendo-se como resultado 278 decisões.

Da análise individualizada dessas 278 decisões chegou-se a 20 decisões pertinentes ao tema deste trabalho, sendo que das 258 decisões descartadas da pesquisa 249 decisões possuíam o laudo toxicológico definitivo de drogas, cinco não eram referentes ao crime de tráfico de drogas, uma era de análise de redimensionamento da pena, em uma não estava em discussão a materialidade, uma era referente a embargos de declaração e uma tratava-se de erro material, nela tendo sido colada a ementa de outro processo.

\title{
4.1 SENTENÇAS DE ABSOLVIÇÃO - AUSÊNCIA DE LAUDO TOXICOLÓGICO DEFINITIVO
}

Foi possível verificar que em quatro $\operatorname{processos}^{6}$ o posicionamento do TJPA foi o mesmo: ante a ausência do laudo toxicológico definitivo não há certeza sobre a materialidade do crime de tráfico de drogas, sendo aquele documento imprescindível para condenação, em observância ao princípio do in dubio pro reo. Nesses casos, entendeu-se por impositiva a absolvição. Veja-se um deles:

\begin{abstract}
APELAÇÃO CRIMINAL - ART. 33, CAPUT, DA LEI 11.343/06 - SENTENÇA ABSOLUTÓRIA - PRELIMINAR DE AUSÊNCIA DE INTERESSE RECURSAL SUSCITADA PELO APELADO: REJEITADA - DO MÉRITO: DO PLEITO PELA CONDENAÇÃO DO APELADO COMO INCURSO NAS SANÇÕES PUNITIVAS PREVISTAS NO ART. 33, CAPUT, DA LEI 11.343/06: IMPROCEDENTE, NÃO HÁ NOS AUTOS PROVAS QUE ATESTEM COM CERTEZA A AUTORIA DO RÉU, BEM COMO NÃO FORA JUNTADO LAUDO TOXICOLÓGICO DEFINITIVO PARA A COMPROVAÇÃO DA MATERIALIDADE DO CRIME, PELO QUE A MANUTENÇÃO DA ABSOLVIÇÃO EM OBSERVÂNCIA AO PRINCÍPIO DO IN DUBIO PRO REO É MEDIDA QUE SE IMPÕE - RECURSO CONHECIDO E IMPROVIDO, NOS TERMOS DO VOTO RELATOR. 1 - [...] 2 - MÉRITO 2.1 - DO PLEITO PELA CONDENAÇÃO DO APELADO COMO INCURSO NAS SANÇÕES PUNITIVAS PREVISTAS NO ART. 33, CAPUT, DA LEI 11.343/06 (Apelação criminal 0000791-33.2013.8.14.0006, relator Des. Mairton Marques Carneiro, data de julgamento: 31/08/2017, data da publicação: 04/09/2017).
\end{abstract}

De acordo com os julgados mencionados constatou-se que o TJPA entendeu pela absolvição nos crimes de tráfico de drogas quando nos autos não havia laudo toxicológico definitivo, devendose mencionar que, das quatro decisões, em três nem sequer havia sido apreendida a suposta droga ${ }^{7}$.

\footnotetext{
6 Processos 0000791-33.2013.8.14.0006, 0003299-74.2014.8.14.0051, 0000005-90.2009.8.14.0023 e 000198713.2014.8.14.0003.

7 Processos 0003299-74.2014.8.14.0051, 0000005-90.2009.8.14.0023 e 0001987-13.2014.8.14.0003.
} 


\subsection{RECONHECIMENTO DE NULIDADE - AUSÊNCIA DE LAUDO TOXICOLÓGICO DEFINITIVO}

Seguindo com o exame das decisões, verificou-se que em sete processos $^{8}$ o TJPA considerou que o laudo toxicológico definitivo teria caráter de imprescindibilidade para condenação nos crimes de tráfico de drogas, uma vez que seria utilizado para esclarecer a toxicidade da droga. Diferentemente das demais decisões, contudo, nos acórdãos referidos, o TJPA entendeu que a ausência do laudo toxicológico não gera absolvição e, sim, nulidade da decisão, conforme o seguinte exemplo:

EMENTA:APELAÇÃO PENAL. ART. 33, CAPUT, DA LEI N 11.343/2006. SENTENÇA CONDENATÓRIA. AUSÊNCIA DE MATERIALIDADE DO DELITO DE TRÁFICO DE ENTORPECENTES, ANTE A NÃO JUNTADA DO LAUDO TOXICOLÓGICO DEFINITIVO. HIPÓTESE QUE NÃO ACARRETA ABSOLVIÇÃO, MAS NULIDADE DO DECISUM PARA PROLAÇÃO DE NOVA DECISÃO, APÓS A JUNTADA DA PROVA PERICIAL E INTIMAÇÃO DAS PARTES PARA CIÊNCIA DA PROVA PERICIAL. NULIDADE DA SENTENÇA DECLARADA. MATÉRIA DE ORDEM PÚBLICA. RECURSO CONHECIDO E PROVIDO. 1. É cediço que o laudo de constatação se presta apenas para atestar a materialidade do crime, em um juízo inicial, a fim de autorizar a lavratura do auto de prisão em flagrante e o recebimento da denúncia, visto que comprova, de maneira precária, a apreensão de substância entorpecente. Por conseguinte, para a prolação de um édito condenatório, imprescindível a confecção do laudo definitivo, a fim de esclarecer e confirmar a toxicidade da droga, através de inúmeros exames técnicos laboratoriais aptos a comprovar a presença da substância que gera a dependência física ou psíquica do indivíduo, bem como seus efeitos farmacológicos. 2. Restou pacificado por esta 1a Câmara Criminal Isolada, que a prolação de sentença pela prática do delito de tráfico de entorpecentes, sem que tenha sido juntado aos autos o laudo toxicológico definitivo, acarreta a nulidade absoluta da sentença, em face da violação aos princípios do contraditório, da ampla defesa e do devido processo legal. 3.Considerando a ausência do Laudo Toxicológico Definitivo no presente feito, não há outra alternativa a esta Relatora, senão, decretar a nulidade da sentença penal condenatória vergastada, a fim de que outra decisão seja proferida em seu lugar, após a juntada do exame pericial atestando a natureza e a quantidade do material apreendido com $\mathrm{o}$ Recorrente. 4. RECURSO CONHECIDO E PROVIDO, À UNANIMIDADE. (Apelação Criminal 0070029-44.2016.8.14.0133, relator Desa. Vânia Lúcia Silveira, data de julgamento: 12/05/2017, data da publicação: 23/05/2017).

Percebe-se das decisões que o laudo é visto, pela sua importância para determinar a materialidade, como prova indispensável à condenação. Isso ocorre devido à realização de diversos exames técnicos laboratoriais aptos a comprovar a presença da substância que gera dependência física ou psíquica do indivíduo, algo que não pode ser suprido pelo laudo provisório ou por qualquer outro meio de prova, incluindo a confissão do acusado.

8 Processos $0070029-44.2016 .8 .14 .0133, \quad 0013959-36.2013 .8 .14 .0028, \quad 0007130-68.2015 .8 .14 .0028, \quad 0004843-$ 69.2014.8.14.0028, 0001528-48.2014.8.14.0023, 0000887-56.2015.8.14.0013 e 0000013-85.2011.8.14.0030. 


\subsection{PRESCINDIBILIDADE DO LAUDO TOXICOLÓGICO DEFINITIVO}

Finalizando a análise dos processos selecionados, verificou-se que em nove deles ${ }^{9}$ o TJPA decidiu pela prescindibilidade do laudo toxicológico definitivo, ante a existência de outros meios de prova a demonstrar a existência da droga e a ocorrência do delito, tais como laudo de constatação provisório, confissão do acusado e depoimentos colhidos, não se devendo falar, em tais circunstâncias, em absolvição. Veja-se uma dessas decisões:

EMENTA: CRIMINAL. APELAÇÃO PENAL. ART. 33 DA LEI N.o 11.343/06. PRELIMINAR DE NULIDADE. AUSÊNCIA DE LAUDO TOXICOLÓGICO DEFINITIVO. REJEITADA. POR MAIORIA DE VOTOS. MÉRITO. MAIOR PATAMAR DE REDUÇÃO PELA CAUSA DE DIMINUIÇÃO DO ART. 33, § 40, DA LEI N.o 11.343/06. SUBSTITUIÇÃO DA PENA PRIVATIVA DE LIBERDADE POR RESTRITIVA DE DIREITOS. ALTERAÇÃO DO REGIME PRISIONAL. PROVIMENTO PARCIAL. 1. É prescindível para a comprovação da materialidade delitiva do crime de tráfico ilícito de entorpecentes a juntada de laudo toxicológico definitivo, se há circunstâncias de fato que caracterizam a conduta típica. Preliminar rejeitada, por maioria. 2. [...]. 5. Recurso conhecido e parcialmente provido. Decisão unânime. (Apelação Criminal 000062826.2011.8.14.0021, relator Des. Raimundo Holanda Reis, data de julgamento: 09/03/2017, data da publicação: 14/03/2017).

Nesses exemplos, o TJPA decidiu pela prescindibilidade do laudo toxicológico definitivo, sendo relativizada a regra prevista na Lei 11.343/06 sobre a elaboração desse laudo para comprovação da materialidade do delito, não se aplicando a regra, portanto, de forma absoluta. Cabe ressaltar ainda que, em 25/04/2018, o TJPA pacificou esse entendimento, mediante edição da Súmula nº 32:

\footnotetext{
Súmula $n^{0}$ 32: A ausência de laudo toxicológico definitivo não conduz, necessariamente, à inexistência de prova de materialidade do crime, a qual poderá ser comprovada por outros elementos probatórios.
}

Essa súmula demonstra que o posicionamento adotado pelo TJPA em relação à necessidade do laudo toxicológico definitivo para a comprovação da materialidade do crime de tráfico de drogas é pela prescindibilidade de tal laudo, podendo ser o crime comprovado por outros meios probatórios. Para isso deve-se chamar a atenção. Não se deve ignorar, por exemplo, que muitas vezes tais condenações ocorrem exclusivamente com base no depoimento da autoridade policial, conforme se verifica na decisão abaixo:

Ementa/Decisão:

EMENTA: APELAÇÃO CRIMINAL. TRÁFICO. ART. 33, CAPUT, DA LEI N 11.343/06. SENTENÇA CONDENATÓRIA. PLEITO ABSOLUTÓRIO. NEGATIVA DE AUTORIA. INSUFICIÊNCIA PROBATÓRIA. PRINCÍPIO DO IN DUBIO PRO REO. INOCORRÊNCIA. MATERIALIDADE E AUTORIA COMPROVADAS.

9 Processos n: 0000628-26.2011.8.14.0021, 0008606-81.2013.8.14.0006, 0005121-68.2014.8.14.0061, 000349698.2014.8.14.0028, 0000075-03.2014.8.14.0028, 0009640-93.2011.8.14.0028, 0004596-59.2012.8.14.0028, 0007925-16.2011.8.14.0028 e 0007876-38.2012.8.14.0028. 
CULPABILIDADE DEMONSTRADA. DEPOIMENTO SÓLIDO DOS POLICIAIS MILITARES QUE EFETUARAM A PRISÃO EM FLAGRANTE DO ACUSADO. EFICÁCIA PROBATÓRIA INQUESTIONÁVEL. PROVAS TESTEMUNHAIS E MATERIAIS SEGURAS. DESCLASSIFICAÇÃO DO CRIME DE TRÁFICO PARA O CRIME DE USO. CONDIÇÃO DE USUÁRIO NÃO COMPROVADA PELO APELANTE. ESTRATÉGIA DE DEFESA. MATERIAL APREENDIDO, NATUREZA E QUANTIDADE DA DROGA, ALÉM DA CIRCUNSTÂNCIA DA PRISÃO CONDIZENTES COM A TRAFICÂNCIA. CONJUNTO PROBATÓRIO QUE AUTORIZA A CONDENAÇÃO. DOSIMETRIA. REDUÇÃO DA PENA-BASE AO MÍNIMO LEGAL ESTABELECIDO PELO LEGISLADOR. IMPOSSIBILIDADE. PRESENÇA DE CIRCUNSTÂNCIAS JUDICIAIS FAVORÁVEIS E DESFAVORÁVEIS. FUNDAMENTAÇÃO IDÔNEA POR PARTE DO JUÍZO. RECURSO CONHECIDO E IMPROVIDO. DECISÃO UNÂNIME. 1. As alegações do apelante acerca da insuficiência de provas e da negativa de autoria não merecem prosperar, eis que se afastam completamente do contexto probatório existente nos autos, o qual satisfaz plenamente o édito condenatório. 2. Inexiste motivo para que se coloque em dúvida a veracidade dos depoimentos dos policiais militares, uma vez que, seguros na narrativa do fato e coerentes em suas declarações, merecem credibilidade. [...]

(TJPA. Processo: 2017.01888764-71. Apelação. $1^{\mathrm{a}}$ Turma de direito penal. Relator: Vania Lucia Carvalho da Silveira. Data de Julgamento: 09/05/2017. Data de Publicação: 16/05/2017)

Este dado também foi apontado na pesquisa “Tráfico e sentenças judiciais - uma análise das justificativas na aplicação de Lei de Drogas no Rio de Janeiro”, produzida pela Defensoria Pública fluminense e pela Secretaria Nacional de Políticas sobre Drogas (Senad) do Ministério da Justiça ${ }^{10}$. De acordo com a pesquisa, em 53,79\% das condenações por tráfico de drogas, no Rio de Janeiro, a palavra dos policiais foi a única prova usada pelos juízes para fundamentar a decisão. Em 71,14\% eles foram as únicas testemunhas nos processos, e a Súmula 70 do Tribunal de Justiça do Rio de Janeiro inclusive determina a possibilidade de condenação com base no depoimento dos policiais.

Percebe-se assim a fragilidade dessas condenações que ignoram a necessidade imperiosa do laudo e se norteiam por um testemunho indireto, tendo em vista que a autoridade policial, em regra, chegará no local do crime após o fato. A importância dada ao depoimento policial ignora que este está diretamente envolvido no caso e tem interesse na condenação. Além disso, impõe uma lógica autoritária em que a palavra de um cidadão tem mais valor do que a de outro, ao arrepio do princípio da presunção de inocência.

\subsection{O DESRESPEITO AOS PRINCÍPIOS E GARANTIAS CONSTITUCIONAIS}

É possível verificar que, embora haja a previsão legal de que a materialidade do crime de tráfico de drogas só poderá ser devidamente comprovada por meio da emissão do laudo toxicológico definitivo (capaz de efetivamente constatar o agente ativo da substância apreendida, para confirmar

10 Conforme matéria publicada em 23/02/2018, a "Palavra de policiais é o que mais influencia juízes em casos de tráfico, diz pesquisa”. Disponível em: https://bit.ly/328LxI4. Acesso em: 15 jan. 2020. 
se ela está ou não na Portaria 344/98 da Anvisa), o TJPA tem decidido pela prescindibilidade de tal laudo. Esse entendimento foi sedimentado com a Súmula 32.

Deve-se notar que, em que pese o fato de, das decisões analisadas, nove serem sobre a prescindibilidade do laudo, em quatro decidiu-se pela absolvição e em sete pela nulidade da decisão. Isso evidencia que há ainda um debate relevante sobre a importância do laudo, o qual a súmula pode esvaecer. Ainda deve-se considerar que das 278 decisões, em 249 decisões havia o laudo toxicológico definitivo. Isso mostra que há uma realidade de produção do laudo, podendo-se considerar a não produção como excepcional.

Ao se considerar que o laudo toxicológico definitivo é prescindível estão sendo ofendidos vários princípios e garantias constitucionais. Em primeiro lugar, ofende-se o princípio da legalidade quando se deixa de preencher o requisito da comprovação da materialidade do tipo penal que tem taxativa previsão legal. Faz-se, assim, com que surja insegurança jurídica em relação ao fato tido como crime, já que não é mais necessária a comprovação da substância tida como proscrita pela portaria. Para Juarez Cirino dos Santos (2010), o princípio da legalidade é o mais importante instrumento de proteção individual no Estado Democrático.

Verifica-se também a ofensa ao princípio in dubio pro reo, tendo em vista que o acusado não possui mais a garantia de que, em caso de dúvida, haverá a decisão pela sua inocência; pelo contrário, passa-se a considerar o acusado culpado, independentemente da comprovação da materialidade do crime. Isso causa um comprometimento democrático em que o juiz condena sem provas definidas em lei. Nos termos constitucionais, a dúvida enseja a absolvição, o que rima com uma estrutura de contenção regrada do poder punitivo (KHALED JÚNIOR, 2013).

Ademais, há a violação ao princípio da verdade. Segundo Aury Lopes Júnior (2016), esse deve ser tido como salvaguarda de que o Estado somente irá atuar dentro da lei e que apenas o que for produzido materialmente dentro dos limites da lei poderá ser utilizado como prova para se chegar à “certeza” dos fatos. Esse princípio é assim desconsiderado, tendo em vista que não importa se a prova material legal não foi produzida, pois mesmo assim, o acusado estará sujeito à condenação por um crime sem prova material (LOPES JÚNIOR, 2016).

Outro princípio que se deve ressaltar é o do livre convencimento motivado, pelo qual o juiz deve avaliar as provas produzidas para servirem de fundamentação para uma decisão. Esse princípio também é violado ao não se observar de maneira adequada a comprovação da materialidade do crime, condenando-se mesmo com ausência de provas idôneas.

Ocorre a relativização de uma regra legal - a elaboração do laudo toxicológico definitivo para a comprovação da materialidade do delito - para prejudicar o acusado, condenando-o sem prova 
apta para demonstrar de forma absoluta a materialidade do crime de tráfico de drogas, em uma clara ofensa aos princípios acima citados.

Conforme previsto em lei, sempre que uma infração deixar vestígios, será necessária a realização do exame de corpo de delito para sua comprovação. Esse é o meio idôneo de demonstração da verdade e é tido como uma garantia ao acusado, que poderá contar com formas próprias de comprovação de determinados fatos. No caso em questão, esse é o exame toxicológico definitivo, realizado por perito que possua conhecimento científico na área para averiguar a composição da substância apreendida, tida como droga.

Considerar a materialidade do crime de tráfico de drogas sem que seja realizado o exame para comprovação da substância é ir contra tais garantias processuais. Ressalta-se que, embora não exista hierarquia de provas no processo penal, existe o que se chama de especificidade de provas. Quando a demonstração de determinado fato só puder ser obtida por certo meio de prova que necessite de meios específicos para sua comprovação, tal meio de prova não poderá ser substituído por outro que não tenha o condão de demonstrar de forma absoluta a existência da materialidade do fato.

O desrespeito aos princípios e garantias processuais demonstra permanências inquisitórias e proibicionistas. O TJPA tem ignorado esses princípios e garantias, aplicando e revalidando decisões de juízes de primeiro grau, que insistem em manter uma lógica inquisitorial, punitivista e proibicionista. Busca-se a condenação do acusado, independentemente da prova produzida, em um papel de acusador.

Para Valois (2017, p. 58), a prisão tem sido tratada, especialmente em relação aos crimes de drogas, como a única solução para um problema que é, na verdade, político:

A solução mágica da prisão é um lavar as mãos que agrava a situação, aumenta a violência
na sociedade e nos emudece para o debate político acerca de um problema que só pode ter
solução política. Solução única, a prisão tem sido ratificada nos tratados internacionais
independentemente de que prisão se esteja falando, não importando que seja uma prisão mais
perigosa do que qualquer droga, que mate mais, que violente mais, bastando que sirva para
demonstrar que todos estão contra as drogas. E, pior, sendo a prisão já ponto pacífico, como
punição padrão para uma prática comercial voluntária, o argumento prisão vai perdendo
força, fazendo com que reste um único outro argumento: penas maiores.

A lógica inquisitorial ainda presente faz-se maior à medida que os julgadores assumem o papel de acusadores e justiceiros, passando por cima de princípios para chegar à “verdade” em que se acredita, que é a da punição. O Judiciário, que deveria ser um poder responsável pela proteção dos direitos, firme e coerente, expõe-se com sua própria política de drogas, sendo mais polícia do que a polícia (VALOIS, 2017). 


\section{CONSIDERAÇÕES FINAIS}

O presente trabalho teve como objetivo analisar as decisões do Tribunal de Justiça do Estado do Pará acerca do tema da materialidade do tráfico de drogas, depreendida do laudo toxicológico definitivo. Foi verificado se esse tribunal considerava o laudo toxicológico definitivo como imprescindível para a condenação pelo crime de tráfico de drogas.

A análise das decisões indica que o posicionamento do TJPA pode ser dividido em três grupos: o primeiro deles considerou o laudo toxicológico definitivo como imprescindível e, a sua ausência, fundamento para absolvição; o segundo grupo considerou o laudo definitivo imprescindível, mas não reconheceu sua ausência como causa de absolvição, apenas de reconhecimento de nulidade para que o processo retornasse ao juízo de $1^{\circ}$ grau para juntada do laudo definitivo e, finalmente, o terceiro grupo considerou o laudo toxicológico definitivo como prescindível nos casos em que fosse possível demonstrar por outros meios a materialidade do crime. Esse último posicionamento levou, inclusive, em 2018, à edição da Súmula 32 do TJPA.

Deve-se observar que das 278 decisões analisadas, em 249 constava o laudo toxicológico definitivo. Isso mostra que há uma realidade de produção do laudo, e que sua não produção pode ser considerada excepcional. Percebe-se ainda que há um debate relevante sobre a importância do laudo, o qual a súmula pode esvaecer. Ainda assim, a maioria das decisões considerou a ausência do laudo como hipótese de nulidade ou absolvição.

Ademais, não se deve ignorar que o posicionamento sumulado comporta incongruências. Ele demonstra imensa disparidade entre a realidade e o sistema processual penal acusatório, por meio dos princípios garantidores, revelando permanências autoritárias de um inquisitorialismo.

Há previsão legal expressa de que a materialidade nos crimes que deixam vestígios deve ser comprovada pela realização do exame de corpo de delito. Além disso, a própria Lei de Drogas afirma que o laudo provisório será suficiente somente para recebimento da denúncia, devendo ser produzido, na instrução processual, laudo definitivo no qual se constate a natureza da substância apreendida, para verificar se ela se enquadra na lista proscrita pela Portaria 344/98 da Anvisa. A inobservância dessas imposições legais evidencia um sistema penal que busca a condenação a qualquer custo daqueles tidos como "traficantes", como se a exclusão deles do seio da sociedade fosse capaz de resolver todos os problemas sociais. É clara a identificação de resquícios do processo inquisitório nas decisões analisadas, encontrando-se julgadores com grande interesse na condenação dos acusados.

A política proibicionista de guerra às drogas implantou um entendimento, quase irrefutável, de que as drogas seriam o grande mal da sociedade, responsável por gerar a maior parte da violência. 
Esse entendimento impede que se percebam as violações evidentes em decisões que desconsideram a necessidade de prova irrefutável para comprovação da materialidade do crime de tráfico de drogas, a qual seria obtida mediante laudo toxicológico definitivo capaz de atestar a natureza da substância apreendida, assim como por meio da verificação da referência a essa substância na Portaria 344/98 da Anvisa. O desejo indubitável de punição tem permitido que se ignorem os problemas decorrentes das violações processuais e do fracasso da política proibicionista de guerra às drogas.

Assumindo postura de condenação sem provas incontestes, os próprios julgadores tomam parte nessa guerra. Porém, a parte por eles escolhida é aquela que desconsidera, em prol de uma guerra falida, direitos fundamentais, aquela que não produz nenhuma solução para os problemas de violência da sociedade, sendo necessária uma discussão mais ampla acerca das reais questões envolvidas no problema das drogas e das possibilidades de resolução. Quanto aos processos criminais, devem seguir os ditames legais e constitucionais, com foco na redução de danos representados pelo próprio sistema penal.

\section{REFERÊNCIAS}

AMARAL, Augusto Jobim do. Discurso penal e política da prova: nos limites da governabilidade inquisitiva do processo penal brasileiro contemporâneo. 2011. Tese (Doutorado em Altos Estudos Contemporâneos) - Faculdade de Letras, Universidade de Coimbra, Coimbra, 2011.

ANDRADE, Mauro Fonseca. Sistemas processuais penais e seus princípios reitores. 2. ed. Curitiba: Juruá Editora, 2013.

ANDREUCCI, Ricardo Antonio. Legislação penal especial. 13. ed. São Paulo: Saraiva, 2018.

AROCA, Juan Montero. El principio acusatorio entendido como eslogan político. Revista Brasileira de Direito Processual Penal, Porto Alegre, vol. 1, n. 1, 2015, p. 66-87.

AVENA, Norberto. Processo Penal. 9. ed. São Paulo: Método, 2017.

BATISTA, Vera Malaguti. Difíceis ganhos fáceis: drogas e juventude pobre no Rio de Janeiro. Rio de Janeiro: Freitas Bastos, 1998.

BINDER, Alberto. La fuerza de la Inquisición y la debilidad de la República. Política Criminal Bonaerense, [s. l.], n. 1, 2003.

BOITEUX, Luciana; CHERNICHARO, Luciana Peluzio; ALVES, Camila Souza. Direitos Humanos e Convenções Internacionais de Drogas: Em Busca de uma Razão Humanitária nas Leis de Drogas. In: VELCHIA, Marcelo Dalla et al. Drogas e Direitos Humanos: Reflexões em tempos de guerra às drogas [recurso eletrônico]. Porto Alegre: Rede UNIDA, 2017. 
BRASIL. Conselho Nacional de Justiça. Banco nacional de monitoramento de prisões - BNMP 2.0. Cadastro Nacional de Presos. Brasília: Secretaria de Comunicação Social, 2018.

BRASIL. Lei n 11.343, de 23 de agosto de 2006. Institui o Sistema Nacional de Políticas Públicas sobre Drogas - Sisnad; prescreve medidas para prevenção do uso indevido, atenção e reinserção social de usuários e dependentes de drogas; estabelece normas para repressão à produção não autorizada e ao tráfico ilícito de drogas; define crimes e dá outras providências. Diário Oficial da União, Brasília, DF, 24 ago. 2006. Disponível em: https://bit.ly/31OkDoE. Acesso em: 26 nov. 2018.

BRITO NETO, José Araújo de et al. Proibicionismo e políticas de drogas no Brasil. Curitiba: Editora CRV, 2016.

BRITO NETO, José Araújo de; SOUZA, Luanna Tomaz de. Proibicionismo e Controle Social: Reflexões Sobre a Emergência do Conselho Estadual sobre Drogas no Estado do Pará. In: OLIVEIRA, Anna Lins (org.). Segurança pública e justiça: direitos humanos na Amazônia. V. 1. Belém: Cromos Editora, 2015. p. 257-274.

CARVALHO, Jonatas Carlos de. Uma história política da criminalização das drogas no Brasil: A construção de uma política nacional. In: III Seminário Nacional de História: Política, cultura e sociedade. Rio de Janeiro: UERJ, 2011.

CARVALHO, Salo de. A política criminal de drogas no Brasil: estudo criminológico e dogmático da Lei 11.343/06. 8. ed. São Paulo: Saraiva, 2016.

CARVALHO, Salo de. A política criminal de drogas no Brasil: estudo criminológico e dogmático da Lei 11.343/06. 6. ed. São Paulo: Saraiva, 2013.

FERRAJOLI, Luigi. Direito e razão: teoria do garantismo penal. São Paulo: Revista dos Tribunais, 2002.

FIORE, Maurício. A medicalização da questão do uso de drogas no Brasil: reflexões acerca de debates institucionais e jurídicos. In: VENÂNCIO, Renato Pinto; CARNEIRO, Henrique (org.). Álcool e drogas na história do Brasil. São Paulo: Alameda, 2005. p. 257-290.

FIORE, Maurício. O lugar do Estado na questão das drogas: o paradigma proibicionista e as alternativas. 2011. Disponível em: https://bit.ly/2Y6gzz7. Acesso em: 20 nov. 2018.

GONÇALVES, Victor Eduardo Rios; BALTAZAR JUNIOR, José Paulo. Legislação Penal Especial. São Paulo: Saraiva, 2017.

KHALED JÚNIOR, Salah Hussein. A busca da verdade no processo penal: para além da ambição inquisitorial. São Paulo: Atlas, 2013.

LIMA, Renato Brasileiro de. Manual de processo penal. 4. ed. Salvador: Ed. JusPodivm, 2016.

LOPES JÚNIOR, Aury. Direito processual penal. 13. ed. São Paulo: Saraiva, 2016.

NUCCI, Guilherme de Souza. Provas no processo penal. 4. ed. Rio de Janeiro: Forense, 2015. 
PACELLI, Eugênio. Curso de processo penal. 22. ed. São Paulo: Atlas, 2018.

PACELLI, Eugênio; FISCHER, Douglas. Comentários ao Código de Processo Penal e sua jurisprudência. 9. ed. São Paulo: Atlas, 2017.

RAMOS, Renata Cristina Marques Bolonheis. Comunidades Terapêuticas: “Novas” perspectivas e propostas higienistas. 2012. 129 f. Dissertação (Mestrado em Psicologia) - Universidade Estadual de Maringá, Maringá, 2012.

SANTOS, Juarez Cirino dos. Direito Penal: Parte Geral. 4. ed. Florianópolis: Conceito Editorial, 2010.

SHIMIZU, Bruno. O mal estar e a sociedade punitiva: ensaiando um modelo libertário em criminologia psicanalítica. 2015. Tese (Doutorado em Direito) - Programa de Pós-Graduação em Direito da Universidade de São Paulo, São Paulo, 2015.

VALOIS, Luis Carlos. O direito penal da guerra às drogas. 2. ed. Belo Horizonte: Editora D’Plácido, 2017.

ZAFFARONI, Eugenio Raúl. O inimigo no direito penal. 2. ed. Rio de Janeiro: Revan, 2007.

Luanna Tomaz de Souza Doutora em Direito 9Lattes iD: http://lattes.cnpq.br/5883415348673630 E-mail: luannatomaz@gmail.com

Panmella Stephanie Acácio Alves Bacharela em Direito E-mail: panmellastephaniie@gmail.com 